\section{Delays in the Placement of Nasogastric Tube: Where are they?}

\section{David G Smithard ${ }^{1 *}$ and Hazel Irizar ${ }^{2}$}

${ }^{1}$ Consultant in Elderly and Stroke Medicine, Queen Elizabeth Hospital, Lewisham and Greenwich NHS Trust, London, UK

${ }^{2}$ Matron for Medicine FESS, Rehab and Integrated Discharge Team, SDGH Southport and Ormskirk NHS Trust, London, UK

\begin{abstract}
Dysphagia following stroke is common and not too infrequently requires a nasogastric tube to be placed. Often there are delays in the pathway between the timing of a decision to place a NGT and it being available and safe to use. This study has examined the time taken between each phase of the pathway and the time taken over all. 150 stroke patients were recruited from 5 English Hospitals. Majority were severe strokes (NIHSS $>15, \mathrm{mRS}>4$ ). From the time of decision making to NGT readiness was 467.15 minutes. There was no significant difference in timings between hospitals. Stroke severity was not a marker for the length of time taken to pass the NGT. It is likely that the need for radiology played a significant role, but would not count for all the differences. The study has demonstrated that some patients wait a long time for a NGT to be ready for use after the clinical decision has been made regarding its placement.
\end{abstract}

\section{Introduction}

Oral-pharyngeal dysphagia is a recognized complication of acute stroke, affecting between $29-72 \%$ of people depending on the timing of the study [1]. For many the ability to swallow will return rapidly $[2,3]$, but for a small minority the ability to resume eating in a meaningful way will take a longer period of time $[2,4]$.

In the UK all patients presenting acutely with stroke have their ability to swallow screened, within 4 hours, by trained nursing staff,

\footnotetext{
*Corresponding author: David G Smithard, Consultant in Elderly and Stroke Medicine, Queen Elizabeth Hospital, Lewisham and Greenwich NHS Trust, London, UK Tel: +44 02088366000; E-mail: david.smithard@nhs.net
}

Citation: Smithard DG, Irizar H (2018) Delays in the Placement of Nasogastric Tube: Where are they? J Gastroenterol Hepatology Res 3: 015.

Received: March 03, 2018; Accepted: April 03, 2018; Published: April 18, 2018 and where a problem is identified a referral is made to a speech and language therapist for a formal swallowing assessment $[5,6]$.

Where a patient's swallow is assessed as unsafe (and cannot be managed by head positioning or modified diet), where the patient is unable to meet their nutritional needs or there is a need for oral medication a Nasogastric Tube (NGT) is offered to the patient [7]. The question remains as to when a NGT should be deployed. The FOOD study did not find any benefit from the early placement of a NGT and that NGT placement could wait until the $7^{\text {th }}$ day [8]. Recent practice has seen the placement of the NGT on day 2 usually for the administration of medication and subsequently feeding [5].

Following a clinical decision that the placement of the NGT is required; the procedure is often fraught with difficulties and delays, both practical (the NGT will not pass, or gets curled in the throat) and logistical (waiting for a chest radiograph to be performed and then waiting for it to be reported. The, not too uncommon, result is that NGT have been placed late in the day and confirmed as ready to use during the night/early morning when senior staff are not available.

The purpose of this study was to look at current practice and identify the extent of the delay and where the delays were in the system.

\section{Methodology}

Patients were eligible for the study, if they were $>18$ years of age, their primary reason for admission was an acute stroke and they were being clinically managed on an acute stroke unit and required a NGT.

The study was an observational cohort study of current clinical practice. The decision to place a NGT was made by the medical team depending on clinical need. The process for NGT placement followed local clinical practice and local guidelines. Research staff documented timings of the various stages of the process and did not request any change to the current local procedures.

Timing started once a clinical decision had been taken that a NGT was required for the management of the patient's nutritional needs (Figure 1).

The clock stopped once the NGT was assessed as being ready to use (i.e., in the correct position and safe to commence feeding).

Stroke was defined as per the WHO criteria [9] and confirmed by CT or MRI. Stroke severity was assessed by the National Institute for Health Stroke Score (NIHSS) [10] and modified Rankin Score [11].

The Health Research Authority was contacted and they were of the opinion that their approval was not required.

\section{Results}

One hundred and fifty patients from five NHS Trusts (Hospitals) were recruited into the study $82(55 \%)$ were female. The mean age of those recruited was 80.6 years (range 56.2 - 100.9); $130(86.7 \%)$ had an ischaemic stroke confirmed on CT or MRI. The majority of patients recruited had moderate to severe strokes with an NIHSS > 
15 and $\mathrm{mRS}>4$ (Figure 2). Majority of the NGTs were passed by nursing staff (Figure 3 ).

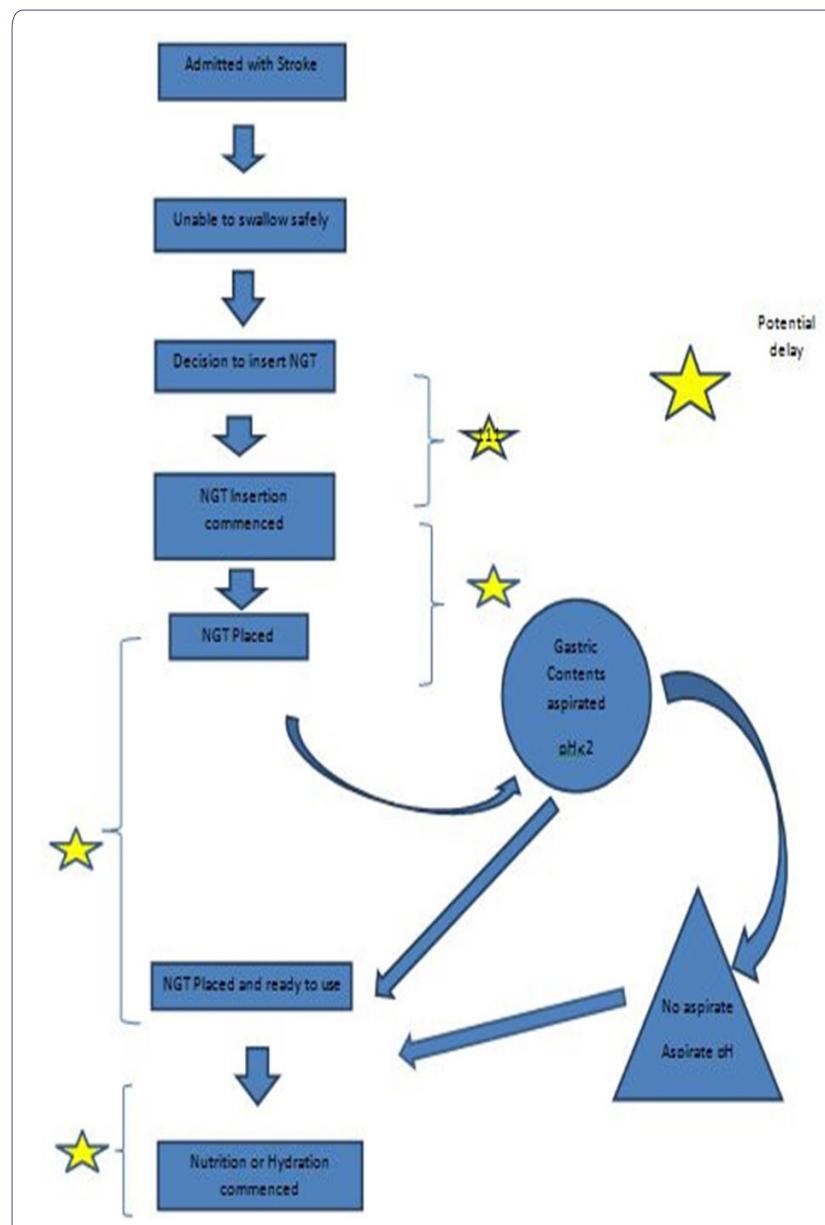

Figure 1: Steps to placement of NGT and places of potential delay.

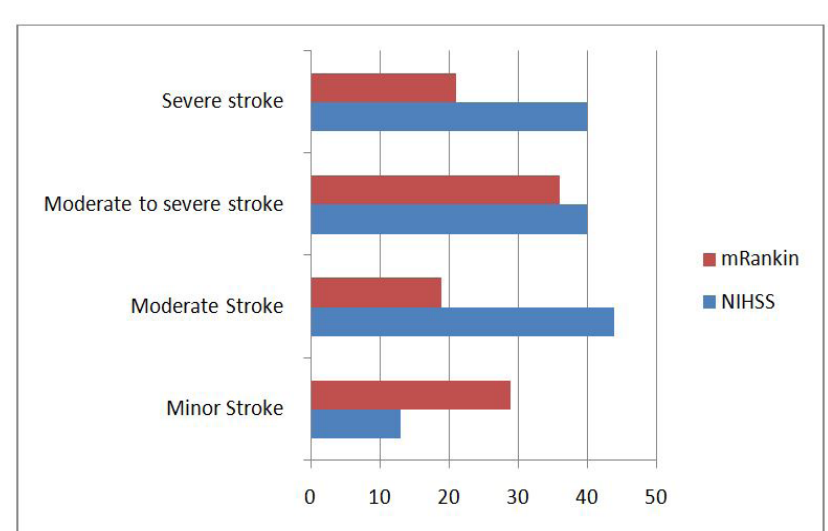

Figure 2: Stroke severity (National Institute of Health Stroke Score (NIHSS) and modified Rankin Scale (mRS)).

The mean time from admission to the decision to place a NGT was 784.6 minutes (median 359.5 minutes), which is more reflection of clinical need than process. The time taken from the clinical decision to deployment of the NGT to its positioning being confirmed was a mean of 467.15 minutes (23 - 4853). The mean time delay between decision and commencement of placement was 977.7 mins (10 - 4727); with a mean time from the commencement of the NGT placement to confirmation of correct positioning being 333.9 minutes (60 - 4035). Dichotomizing the results in to two, NIHSS $<16$ and $16+$ suggested that those people with a greater NIHSS were more likely to wait for the tube to be ready for use $(452.9$ mins vs. 74.1 mins $p=$ NS) particularly between confirmation and use (737.4 mins vs. 900.9 mins $\mathrm{p}=\mathrm{NS}$ ) (Figures 4 and 5).

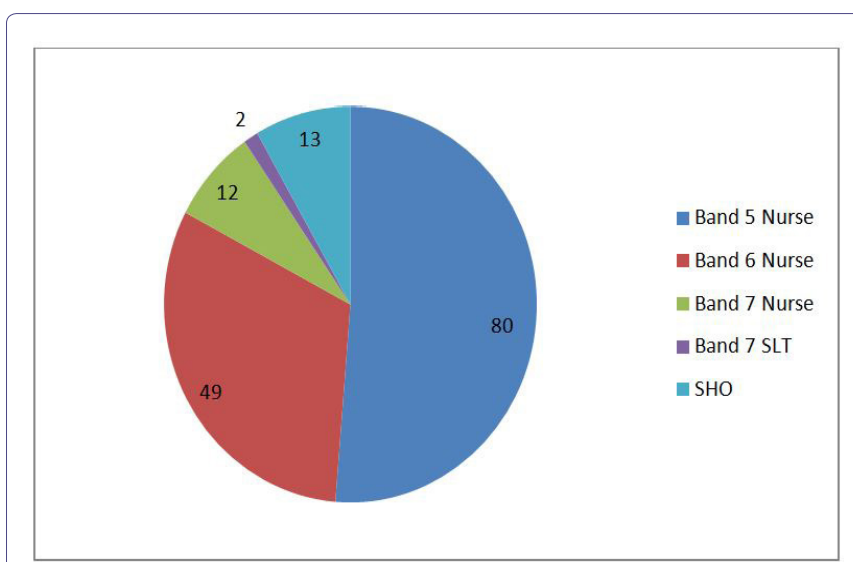

Figure 3: Staff and Seniority of staff placing NGT.

Band: Seniority; SLT: Speech and Language Therapist/ Pathologist; SHO: Trainee doctor

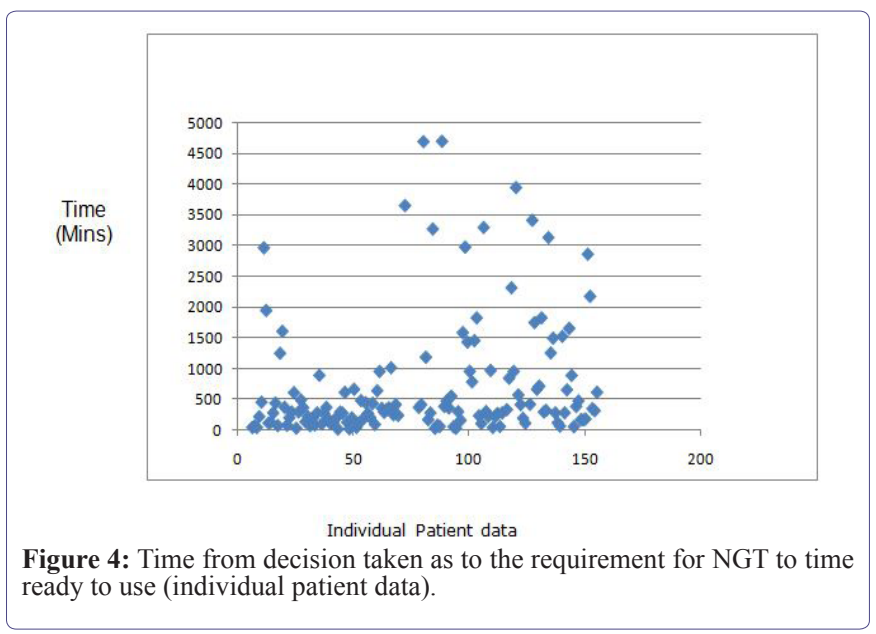

There was no correlation between the time taken to confirmation of a NGT to be ready for use and its actual use $(\mathrm{P}=0.071)$. There was no significant difference between hospitals as to the time taken to insert the tube and it to be ready for feeding. There was a non-significant difference in the frequency of chest film use between hospitals Centre 5: $71.9 \%$ vs. Centre $47.1 \%$; but the numbers were small in some of the groups (Table 1).

$38 / 150$ of people recruited only required one attempt to pass an NGT. There were $42(28 \%)$ cases of presumed aspiration pneumonia following the passing of a NGT. 


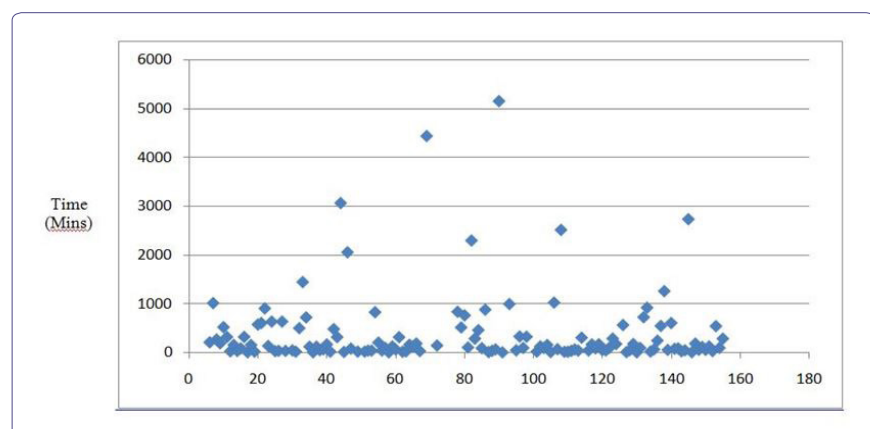

Individual Patient data

Figure 5: Time from NGT being ready for use to feeding commencing (Individual patient data).

\begin{tabular}{|c|c|c|c|c|c|}
\hline Hospital & N & $\begin{array}{c}\text { Number (\%) CXR } \\
\text { undertaken }\end{array}$ & $\begin{array}{c}\text { Mean time } \\
\text { (Mins) }\end{array}$ & $\begin{array}{c}\text { Median time } \\
\text { (Mins) }\end{array}$ & Range (Mins) \\
\hline 1 & 49 & $31(63)$ & 748 & 360 & $61-3948$ \\
\hline 2 & 50 & $14(28)$ & 431.9 & 283 & $23-2968$ \\
\hline 4 & 14 & $1(7.1)$ & 1300.4 & 975 & $50-3655$ \\
\hline 5 & 32 & $23(71.9)$ & 962.9 & 320 & $35-4700$ \\
\hline 6 & 26 & $5(19.2)$ & 1036.4 & 451 & $210-3416$ \\
\hline
\end{tabular}

Table 1: Number Chest X-Rays (CXR) undertaken and time taken for NGT to be ready for use from time of decision per Hospital.

$\mathrm{N}$ : Number recruited at the Hospital.

\section{Discussion}

Dysphagia following stroke is very common, and in a few may persist of a very long time [2,3]. For many people with difficulties swallowing on admission, problems will have resolved in the first 48 hours and oral feeding will be able to be commenced. Where the swallow is not resolving, or the swallow has not returned significantly to support nutritional requirements, enteral support is required. Where the patient been without nutrition for more than a week, complications with refeeding occur and delays on commencement in this situation will potentially adversely affect clinical outcome. NGTs are used in many other clinical scenarios (Malignancy and oesophageal fistula for example), and as such the concerns highlighted will be relevant to these patients also.

The placement of an NGT is not without its risks. A NGT may be placed into the lung resulting in trauma to vocal cords, bronchi or lung tissue $[12,13]$. However, the prevalence of adverse events other than pneumothorax arising from misplacements is uncertain. In clinical studies, inadvertent placement into the bronchi occurs in $2 \%$ to $4 \%$ of conventional insertions of NGTs [14-16]. Studies have shown that $18.7 \%-26 \%$ of the NGTs misplaced into the bronchial tree resulted in pneumothoraces, while $2.7 \%$ were fatal $[14,15]$.

The decision to provide enteral nutrition needs to be based on clinical need, the timing of which may vary between patients. The RCP guidelines for enteral nutrition [7] comment that enteral feeding should commence when oral intake is absent or is likely to be absent for 5-7 days [7]. The latest RCP guidelines recommend feeding within 24 hours of not being able to meet nutritional needs, which may result in some people being fed enterally unnecessarily [5]. The Food trial results did not find any difference in outcome between early and delayed enteral feeding [8]. The mean time from admission and the decision to place a NGT was just over half a day. There may be good clinical reasons for this, but potentially some will have a NGT placed for a very short time period. Further work is needed to examine this.

Once a clinical decision has been made that a NGT is required to support nutritional and hydration needs, placement should occur in a timely manner. This study found that there were, in some instances large variations in practice with time taken between 23 mins and > 82 hours. NGTs will need to be placed by someone with training and experience. In this study $89.3 \%$ were placed by nursing staff, $(80 \%$ $(120 / 150)$ by band 5 and 6$)$, whereas medical trainees only placed $8.7 \%$. This is in line with clinical practice; however this may leave medical staff significantly deskilled, which is a clinical risk, especially as they are frequently called up on by the nursing team when difficulties arise.

The incidence of aspiration pneumonia was $28 \%$ in this study. This was a select group of stroke patients with persistent swallowing problems, and significant stroke severity (NIHSS $>15$ ) on admission. The infection was on balance due to inhalation of infected saliva as recent studies suggest that the presence of a NGT does not increase the risk of aspiration pneumonia [17,18].

This study has confirmed that for some people the time taken for a NGT to be passed and be ready for use is long. What is more surprising is the length of time taken to commence enteral feed after a NGT has confirmed its position. Delays overnight may be understandable, but delays of several days are more difficult to explain. Where a NGT has been confirmed as in place during the late evening/early morning, it is reasonable to delay the commencement of feeding until the morning. Work load, staffing levels and logistics of obtaining an X-ray will contribute to some of the shorter delays.

In England, the National Health Service has specified that the positioning of a NGT should be verified prior to its use and errors of placement should be a never event. Given the delays in commencement of placement, guidelines need to be developed which outlines best practice to ensure placement is undertaken in a timely manner, such that this does not occur out of hours to minimize the risk of misplacement of the NGT and misreading of the chest X-ray. Wrong placement of the NGT is classed as a never event and as a consequence many trusts will have guidance on placing a NGT and time of day but not length of time to place from decision [18,19].

This study examined only a small part of the dysphagia story in the context of stroke. When dysphagia is prolonged, alternative enteral methods of feeding are used, such as Percutaneous Endoscopic Gastrostomy (PEG), where an enteral tube is inserted through the abdominal wall into the abdomen. When this is not clinically possible, a tube may be placed radiologically (Radiologically Inserted Gastrostomy - RIG), in these instances the enteral tube passes into the jejunum. Similar concerns may be present in these pathways also.

\section{Conclusion}

The use of NGTs in stroke units and acute general hospitals is common. This study has shown that there are, in many instances, significant delays in the NGT placement pathway. Delays occurred between each phase of the pathway (Figure 1). In many cases the delays may not have resulted in a detrimental affect to the patient, however 
feeding was delayed and a route for the delivery of medication was delayed. Clinicians need to investigate ways to improve the pathway rather than accepting the present status quo.

\section{Acknowledgement}

Dean Waugh, Leeds Teaching Hospitals NHS Trust; East Kent Hospitals University NHS Foundation Trust, David Hargroves, Linda Cowie; Colchester Hospital NHS Trust, Alison Wright, Ramachandra Sivakumar King's College Hospital NHS Foundation Trust, James Teo, Laszlo Szithra. Southport and Ormskirk Hospitals NHS Trust, Lucy Enright.

\section{References}

1. Martino R, Foley N, Bhogal S, Diamant N, Speechley M, et al. (2005) Dysphagia After stroke. Stroke 36: 2756-2763.

2. Smithard DG, O’Neill PA, England RE, Park CL, Wyatt R, Martin DF, et al. (1997) The natural history of dysphagia following a stroke. Dysphagia 12: 188-193.

3. Hussain A, Woolfrey S, Massey J, Geddes A, Cox J (1996) Percutaneous endoscopic gastrostomy. Postgrad Med J 72: 581-585.

4. Mann G, Hankey GJ, Cameron D (1999) Swallowing function after stroke: prognosis and prognostic factors at 6 months. Stroke 30: 744-748.

5. Royal College of Physicians (2016) National clinical guideline for stroke (5thedn). National Clinical Guideline for Stroke, London, UK.

6. National Institute for Health and Care Excellence (2010) Stroke in Adults National Institute for Health and Care Excellence, London, UK.

7. Royal College of Physicians of London (2002) Nutrition and patients: a doctor's responsibility/ report of a working party of the Royal College of Physicians. Royal College of Physicians of London, London, UK.

8. Dennis M, Lewis S, Warlow C, FOOD Trial Collaboration (2005) Effect of timing and method of enteral tube feeding for dysphagic stroke patients (FOOD): a multicentre randomised controlled trial. Lancet 365: 764-772.
9. Aho K, Harmsen P, Hatano S, Marquardsen J, Smirnov VE, et al. (1980) Cerebrovascular disease in the community: results of a WHO collaborative study. Bull World Health Organ 58: 113-130.

10. Brott T, Adams HP Jr, Olinger CP, Marler JR, Barsan WG, et al. (1989) Measurements of acute cerebral infarction: a clinical examination scale. Stroke 20: 864-870.

11. Rankin J (1957) Cerebral vascular accidents in patients over the age of 60 . II. Prognosis. Scott Med J 2: 200-215.

12. Sparks DA, Chase DM, Coughlin LM, Perry E (2011) Pulmonary Complications of 9931 Narrow-Bore Nasoenteric Tubes During Blind Placement: A Critical Review. JPEN J Parenter Enteral Nutr 35: 625-629.

13. Sorokin R, Gottlieb JE (2006) Enhancing patient safety during feeding-tube insertion: a review of more than 2000 insertions. JPEN J Parenter Enteral Nutr 30: 440-445.

14. Rao M, Kallam R, Arsalani-Zadeh R, Gatt M, MacFie J (2009) Placing of feeding tubes by the bedside using an electromagnetic sensing device. Br J Intensiv Care Summer 54-59.

15. Dávalos A, Ricart W, Gonzalez-Huix F, Soler S, Marrugat J, et al. (1996) Effect of malnutrition after acute stroke on clinical outcome. Stroke 27: 1028-1032.

16. Taylor S, Allan K, McWilliam H, Manara A, Brown J, et al. (2014) Confirming nasogastric tube position with electromagnetic tracking versus $\mathrm{pH}$ or X-ray and tube radio-opacity. Br J Nurs 23: 352-358.

17. Kalra L, Hodsoll J, Irshad S, Smithard D, Manawadu D, et al. (2016) Association between nasogastric tubes, pneumonia, and clinical outcomes in acute stroke patients. Neurology 87: 1352-1359.

18. Dziewas R, Warnecke T, Hamacher C, Oelenberg S, Teismann I, et al. (2008) Do nasogastric tubes worsen dysphagia in patients with acute stroke? BMC Neurol 8: 28.

19. National Patient Safety Agency (NPSA) (2011) Patient Safety Alert NPSA/2011/PSA002: Reducing the harm caused by misplaced nasogastric feeding tubes in adults, children and infants. National Patient Safety Agency, England, UK. 